\title{
Grid Connected Hybrid Solar and Diesel Generator Set: A Cost Optimization with HOMER
}

\author{
Amevi Acakpovi*, ${ }^{*}$, Mathias B. Michael ${ }^{1}$, Issah B. Majeed ${ }^{2}$ \\ ${ }^{1}$ Electrical and Electronic Engineering Department, Accra Technical University, Accra, Ghana \\ ${ }^{2}$ Electrical and Electronic Engineering Department, Takoradi Technical University, Takoradi, Ghana
}

\begin{tabular}{l} 
A R T I C L E I N F O \\
\hline Article history: \\
Received: 01 April, 2017 \\
Accepted: 14 June, 2017 \\
Online: 26 June, 2017
\end{tabular}

Keywords:

Levelized cost

Hybrid energy supply

Diesel generator

Solar Energy

Grid connected

Emissions

\begin{abstract}
A B S T R A C T
Extensive increases in electricity cost added to the numerous power outages encountered in developing countries has led to the deployment of hybrid energy supplies that mainly ensure continuity of power supply while attempting a reduction of electricity generation cost. This paper, specifically deals with the cost optimization of electricity generation from a grid connected hybrid solar and diesel generator. An electrical audit was first conducted on a selected building: the Electrical Block of Accra Technical University. The load estimate led to a total energy of $234 \mathrm{kWh}$ for all electrical gadgets with the exception of the air-condition systems. The estimate was used to design the hybrid system with HOMER software that resulted in a total capacity of $115 \mathrm{~kW}$ and a levelized cost of electricity of $0.472 \$ / \mathrm{kWh}$ taking into consideration no power outage in the year. Furthermore, the proposed hybrid system was made of a grid connected solar system that supplies the full load with the exception of the air-condition systems while the National Grid is used to cover the rest. In situation of power outages, the Generator Set takes over the National grid while the solar is still connected to the Grid. This mechanism was simulated and the cost of electricity in absence of the grid was estimated at $1.496 \$ / \mathrm{kWh}$. A general cost of electricity taking into consideration $90 \%$ ON period of the grid against 10\% Off period of the grid per year, was estimated to $0.574 \$ / \mathrm{kWh}$. Besides, the proposed system produced savings in emission of carbon dioxide, $26.42 \mathrm{~kg} /$ year, sulfur dioxide, $115 \mathrm{~kg} /$ year and Nitrogen oxides, $56 \mathrm{~kg} /$ year. Finally, the system yielded a very good payback period of 10.43 years with regard to a lifetime of 25 years.
\end{abstract}

\section{Introduction}

Grid supply systems may be classified as On-grid or Off-grid power supplies. Large scale power also referred to as grid power or macro-grid can generate many hundreds of Megawatt, sometimes, up to the gigawatt (GW) with a centralised transmission and distribution system that can cover a country or even beyond.

On the other hand, off-grid system simply signifies power supply system that do not depend on the main grid. They are small in size as compared to main grid systems. Off-grid supplies are

${ }^{*}$ Corresponding Author: Amevi Acakpovi, Electrical and Electronic Engineering Department, Accra Technical University, Accra, Ghana

Email: cakpovia@gmail.com considered autonomous for the reason that they make use of local power generation to supply demand (IRENA, 2015) [1]. Off-grid systems include mini and micro-grids as well as standalone systems. Off-grid power supply may be deployed for a community while stand-alone systems are purposely designed for individual users or individual appliances.

Additionally, a micro-grid is a distributed energy resources comprising of demand management, storage and generation capable of operating in parallel independently from the grid. The primary purpose is to ensure local, reliable, and affordable energy security for urban and rural communities, while also providing solutions for commercial, industrial, and federal government consumers. Nayar (2010), [2] also explained that a stand-alone Micro-Grid system is an isolated small grid that include at least 
diesel generator, inverter, batteries and uses various renewable energy sources available.

Extensive studies have been carried on microgrid hybrid systems including solar, diesel. Sopian \& Othman (2005), [3] presented the performance of a hybrid solar, diesel system. The system uses the solar as a main supply and the diesel generator as an alternative supply. Storage batteries are deployed to save the excess energy produced by solar. According to (Ali et al., 2008; Sopian \& Othman, 2005) [3], [4], hybrid solar-diesel generator increases the reliability of supply, reduces pollution and cost and sustains power continuously. [5] provides guidance in implementing hybrid solar systems and reported on the state of art of some PV-Diesel systems used for rural electrifications. PV/Diesel mini-grid systems have become more attractive with the rising cost of other power resources and the reducing cost of solar panels and accessories. The driving element behind this attraction for solar hybrid system is mainly cost and continuity of supply and convenience. In mountainous areas or desert where it is difficult to deploy national grid, solar is directly the preferred alternative choice as illustrated by (Yilnaz, Ozcalik, Aksu, \& Karapinaar, 2015), [6] who developed a study on planning, modelling and cost analysis of a mini-grid solar PV/Diesel hybrid energy systems for houses installed in Turkey mountains. Yilmaz et al. (2015), [6] found that the cost of hybrid solar PV/diesel though higher than National grid electricity was still acceptable around 0.24 Euro/kWh. Moreover, (Alam \& Bhattacharyya, 2016), [7] proposed a decentralized hybrid mini-grid system with reduced electricity cost between 0.29 and $0.31 \$ / \mathrm{kWh}$ for coastal areas using the HOMER software. Once again the main consideration was cost reduction from a former energy supply system that was solely based on solar.

Microgrid connected systems are basically made of multiple distributed generators known as DGs that connect to the grid through a transfer switch (Nguyen, Won, Ahn, \& Chung, 2012; Parhizi, Lotfi, Khodaei, \& Bahramirad, 2015) [8], [9]. Grid connected system have been compared in several ways to islanded microgrid system with distributed generators mainly made of renewable energies such us solar, wind etc. Othman, Gabbar, Honarmand, \& Othman (2015), [10] perform a similar comparison and found that the islanded microgrid system was more robust and resistant to fault than the grid connected system. However, many studies that aimed at developing power control or energy storage systems for islanded microgrid as illustrated by (Etxeberria, Vechiu, Camblong, Vinassa, \& Camblong, 2010; Pota, Hossain, Mahmud, \& Gadh, 2014) [11], [12], have also realized the complexity involved and the adequacy of such systems only for remote and isolated locations. On the other hand, grid-connected system are advantageous in providing a reduced cost of electricity as the Grid electricity is always considered cheaper than locally developed power. They also provide the advantage of a continuous supply that overcomes the fluctuation of the grid by relying on the alternative supplies.

This paper is interested in grid-connected hybrid systems involving solar and generator set. This comes as a result of the growing interest in developing renewable energies for effective supply of electricity in West Africa, precisely, Ghana. In the recent past, the National grid in Ghana has been earmarked with inefficient and highly intermittent supplies that affected businesses and development in all dimensions (Aryeetey, 2005), [13]. Companies and houses therefore developed the need to be self-autonomous in power provision for their need. The obvious solution was the adoption of solar energy due to the immense availability of solar radiation in Ghana. However the cost of solar is another limiting factor reducing its deployment. Instead of solely relying on solar, it is rather used partly to supply essential but low-consuming appliances like lighting and fans.

The other alternative massively adopted in Ghana to overcome the regular interruption of electricity supply from the grid is Diesel Generator Sets. This solution was embraced as new generators have become very efficient in terms of fuel consumption and can also work with reduced level of noise. Furthermore, the cost of fuel used by the Diesel generator is relatively low as compared to other fuels.

Combining the interest of a highly available solar irradiation in Ghana to the possibility of using Diesel generator at a relatively lower fuel cost, have brought the interest in developing this hybrid solar-diesel generator that will be connected to the microgrid. Though the microgrid components include loads, DERs, master controller, smart switches, protective devices, as well as communication, control and automation systems, (Parhizi et al., 2015), [8], this paper focuses mainly on conceptual design and cost analysis of the system. The rest of the paper presents the hybrid system applied to a case study at Accra and analyses its cost benefits.

\section{Methodology}

A case study approach has been adopted to design the solar-diesel generator hybrid supply. The next paragraph show the framework for designing the hybrid system, the data collected on the selected location, a summary of load audit at the selected location and a design of the hybrid system using Homer.

\subsection{Framework for Designing the Grid-Connected Hybrid Solar and Diesel Generator}

Figure one shows the general design of the system which is made of two bus-bars connected to the PV array, the diesel generator and the grid itself. A converter playing at the same time the role of inverter and rectifier is also connected in bi-directional mode to the busbar. Finally the busbar is connected to the load in unidirectional mode to supply the required electricity.

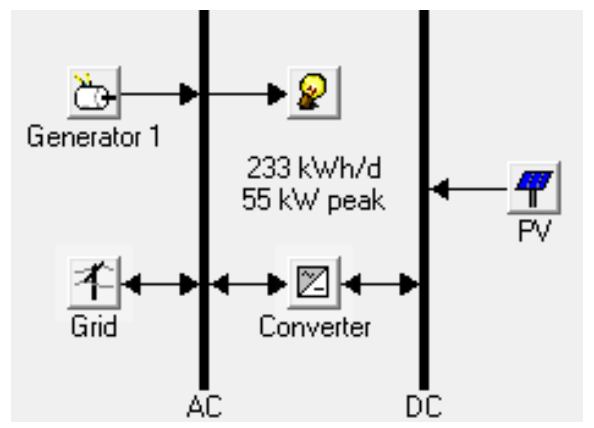

Fig.1: Proposed Model of Grid-Connected Hybrid Solar-Diesel Generator under HOMER 


\subsection{Selected Location and Presentation of Data}

The Electrical block of Accra Technical University has been selected for this study. The geographical parameters of the location are $5.5541^{\circ} \mathrm{N}, 0.2056^{\circ} \mathrm{W}$. It is a four-storey building that covers an area of $12 \mathrm{~m} \mathrm{x} \mathrm{100m,} \mathrm{located} \mathrm{in} \mathrm{the} \mathrm{premises} \mathrm{of} \mathrm{Accra}$ Technical University, formerly known as Accra Polytechnic. The block contains twelve lecture rooms, a computer laboratory, two other multipurpose electrical laboratories, twenty offices for lecturers and eight washrooms. The lecture rooms are busily occupied by students and lecturers for lecturing over the day and are equipped with fans, lighting systems and socket. However the lecturer's offices have Air Conditioning Systems in addition to the fans, light and sockets.

\subsection{Design of the Hybrid System using Homer}

An energy audit is first established as illustrated in the table 1

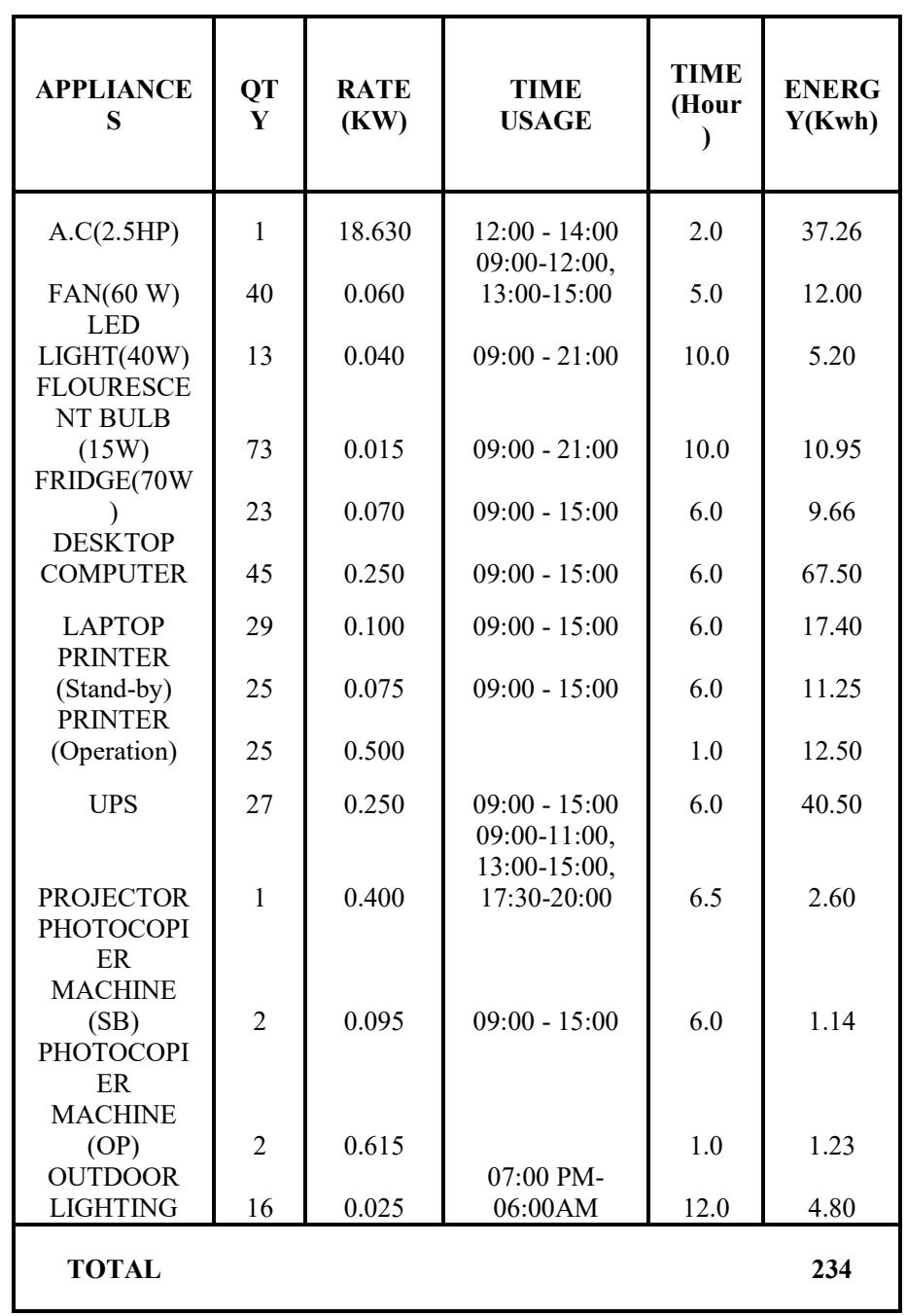

Table 1: Energy Audit

Based on the total energy demand and the system architecture agreed upon, one must estimate the size of various components before selecting them. The sizing of the solar system is based on the determination of renewable energy window which is provided directly from the solar data obtained from NASA site. Knowing the renewable energy window and the daily load deducted from the data, the system's total AC power can be obtained from the equation (1)

www.astesj.com

$$
\begin{aligned}
& P_{A C}=\frac{\text { DailyLoad }(\mathrm{kWh} / \mathrm{d})}{R \cdot \text { E.Window }(\mathrm{h} / \mathrm{d})} \\
& P_{A C}=\frac{234}{10}=23.4 \mathrm{~kW}
\end{aligned}
$$

The AC power is converted to DC power by an inverter with an efficiency of about $90 \%$. This implies that the DC power is obtained as shown in equation (3)

$$
P_{D C}=\frac{P_{A C}}{\operatorname{In} v_{E f f}}
$$

Where $I n v_{E f f}$ stands for Inverter Efficiency

$$
P_{D C}=\frac{23.4}{0.9}=26 \mathrm{~kW}
$$

The calculated DC power is not directly used for the design but rather an Adjusted DC power due to the fact that many other factors, hardly quantifiable, contribute to the system total losses. Some of these include losses in cable, shading environment and others. In view of these, the paper proposed an adjustment factor of $30 \%$ and this has led to the determination of the adjusted DC power as follow

$$
\begin{aligned}
& P_{D C(\text { Adjusted })}=P_{D C} \times \eta \\
& P_{D C(\text { Adjusted })}=26 \times 1.3 \\
& P_{D C(\text { Adjusted })}=33.8 \mathrm{~kW}
\end{aligned}
$$
follow

Subsequently the PV array area A can be determined as

$$
A=\frac{P_{D C(\text { Adjusted })}}{\left(1 k W / m^{2}\right) \times \eta_{P V}}
$$

Where $\eta_{P V}$ is the PV system efficiency?

$$
\begin{gathered}
A=\frac{33.8}{1 \times 0.15} \\
A=225.33 m^{2}
\end{gathered}
$$

The next after determining the PV array's area is to estimate the solar system's capacity. The system's total energy received from the solar PV area is calculated based on equation (11) below

$$
E_{T}=G \times A
$$

Where $\mathrm{G}$ is the solar radiation from the area and $E_{T}$ the total energy. 
A. Acakpovi et al. / Advances in Science, Technology and Engineering Systems Journal Vol. 2, No. 4, 92-98 (2017)

$$
\begin{aligned}
& E_{T}=5.1 \times 225.33 \\
& E_{T}=1149.18 \mathrm{kWh}
\end{aligned}
$$

The system capacity can therefore be inferred with consideration to the renewable energy window as follow

$$
\begin{gathered}
C=\frac{E_{T}}{R E_{\text {Window }}} \\
C=\frac{1149.18 \mathrm{kWh}}{115} \\
C=115 \mathrm{~kW}
\end{gathered}
$$

\section{Result}

This section presents the simulation results generated from the HOMER for the grid connected system followed by a scenario where power outage was simulated. The specifications of the solar panel used can be found in Appendix, Table A1.

\subsection{Results from Grid Connected Systems}

Table 2 and 3 show respectively the system architecture and cost summary. It can be observed that the PV array is sized with the designed capacity of $115 \mathrm{~kW}$, the diesel generator is selected with a rating slightly above the solar array capacity, $150 \mathrm{~kW}$ so that it can fully replace the solar array in case of maintenance or breakdown.

\begin{tabular}{|l|l|}
\hline Energy Sources & Power Ratings \\
\hline PV Array & $115 \mathrm{~kW}$ \\
\hline Generator & $150 \mathrm{~kW}$ \\
\hline Grid & $1000 \mathrm{~kW}$ \\
\hline Inverter & $75 \mathrm{~kW}$ \\
\hline Rectifier & $75 \mathrm{~kW}$ \\
\hline
\end{tabular}

Table 2: System's Architecture

\begin{tabular}{|l|l|}
\hline Cost Elements & Cost (\$) \\
\hline Total net present cost & 133.53 \\
\hline Levelized cost of energy & 0.472 \\
\hline Operation cost & $-7.476 / \mathrm{yr}$ \\
\hline
\end{tabular}

Table 3: Summary of cost

The estimated electrical energy produced by the different sources over a year is also presented in Table 4 and illustrated in Figure 2. It can be observed that the solar has been used as the main alternative to supply energy to the load and this is supported by the grid in case the solar energy becomes insufficient to meet the load. Because the diesel generator is meant to operate as alternative supply when the solar plant is faulty, no energy supplied by the generator can actually be observed in Figure 2 .

\begin{tabular}{|l|l|l|}
\hline Components & Production (kWh/yr) & Fraction \\
\hline PV Array & 143.216 & $88 \%$ \\
\hline Generator & 0 & $0 \%$ \\
\hline Grid Purchase & 20.033 & $12 \%$ \\
\hline Total & 163.249 & $100 \%$ \\
\hline
\end{tabular}

Table 4. Energy Production per Sources

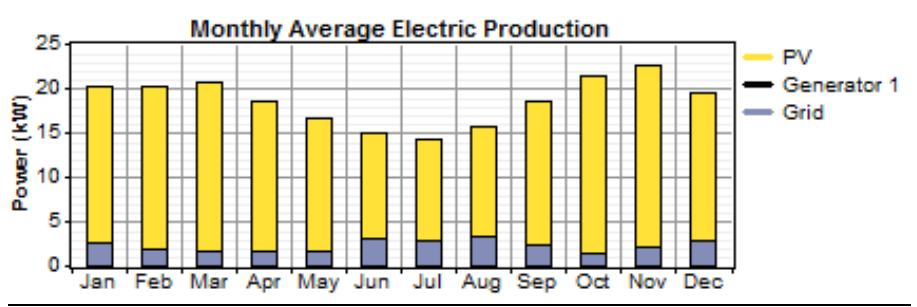

Fig.2: Energy production from various sources on a monthly basis

The load consumption as well as system results including excess electricity, unmet load and capacity shortage are respectively presented in Table 5 and 6 .

\begin{tabular}{|l|l|l|}
\hline Load & Consumption (kWh/yr) & Fraction \\
\hline AC primary load & 85,045 & $58 \%$ \\
\hline Grid Sales & 61.837 & $42 \%$ \\
\hline Total & 146.882 & $100 \%$ \\
\hline
\end{tabular}

Table 5. Load consumption profile

\begin{tabular}{|l|l|}
\hline Load & Consumption (kWh/yr) \\
\hline Excess Electricity & 2.272 \\
\hline Unmet load & 0.00 \\
\hline Capacity shortage & 0.00 \\
\hline Renewable Fraction & 0.877 \\
\hline
\end{tabular}

Table 6. Consumption parameters

Furthermore, the savings in terms of emissions are presented in Table 7.

\begin{tabular}{|l|l|}
\hline Pollutant & Emissions (kg/yr) \\
\hline Carbon dioxide & -26.420 \\
\hline Carbon monoxide & 0 \\
\hline Unburned hydrocarbon & 0 \\
\hline Particulate matter & 0 \\
\hline Sulfur dioxide & -115 \\
\hline Nitrogen oxides & -56 \\
\hline
\end{tabular}

Table 7. Emissions 


\subsection{Scenario of Power Outage Simulation}

A power outage situation is considered in this scenario where the grid has been put off to mimic power outages, a recurrent situation encountered in developing countries. The model of the system without the grid contribution is illustrated in Figure 3

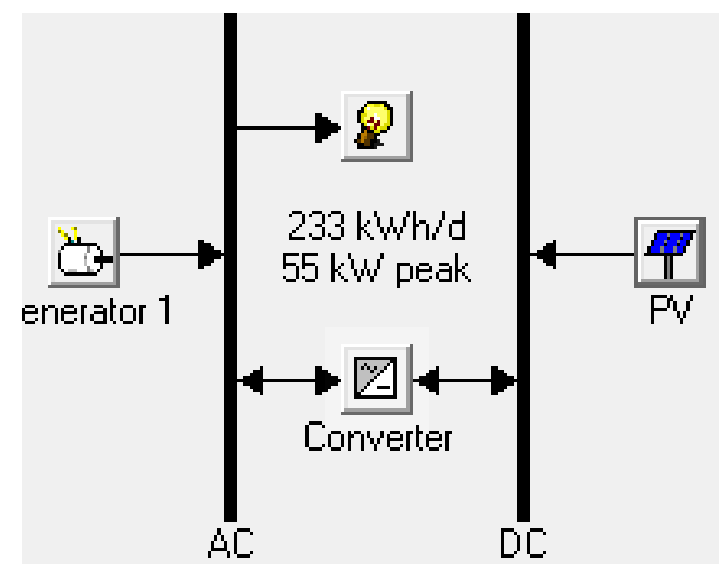

Fig.3: Model of Grid- Connected System in case of power outage

Simulation results obtained from the HOMER, show the cost summary below

\begin{tabular}{|l|l|}
\hline \multicolumn{1}{|c|}{ Cost Elements } & \multicolumn{1}{c|}{ Cost } \\
\hline Total net present cost & $\$ 1,086,070.00$ \\
\hline Levelized cost of energy & $1.496 \$ / \mathrm{kWh}$ \\
\hline Operation cost & $\$ 252,496.00$ \\
\hline
\end{tabular}

Table 8 . Summary of cost

It can be observed that the levelized cost of electricity has significantly increased and this is justified by the fact that the supply was mainly based on the generator set (57\%) that uses diesel. Similarly, it is interesting to observe that the PV system contribution was almost the same as illustrated in both Table 9 and Figure 4. This confirms the configuration of the inverter to synchronize with the Grid as well the gennerator perfectly. In other terms the cost of electricity in absebnce of the Grid would have been higher than the one shown in Table 8 if the Generator was the sole source of supply. The solar contribution which is highly significant (43\%), helped to minimize the cost of electricity in power outage.

\begin{tabular}{|l|l|l|}
\hline Components & Production $(\mathbf{k W h} / \mathbf{y r})$ & Fraction \\
\hline PV Array & 186803 & $43 \%$ \\
\hline Generator & 247247 & $57 \%$ \\
\hline Total & 434050 & $100 \%$ \\
\hline
\end{tabular}

Table 9. Energy production per sources in case of power outage

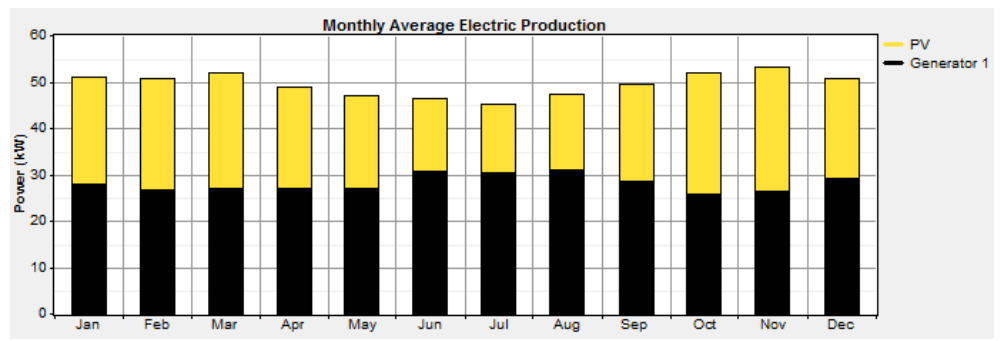

Fig.4: Energy distribution per sources in case of power outage

\subsection{Estimation of Final Electricity Cost}

The cost of electricity is estimated as a weighted sum of the levelized cost of electricity during ON grid and OFF grid period respectively. A rough estimate of power outages at Accra based on recent data on electricity supply shows that the power outage period in the year is about 30 to 36 days making approximately $10 \%$ of the duration of the year. The formula below applies for the calculation of the cost of electricity over a year taking into consideration the On and Off periods of the Grid.

$$
\begin{gathered}
\operatorname{Cost}_{\text {Final }}=90 \% \cdot \text { Cost }_{\text {Grid_On }}+10 \% \cdot \text { Cost }_{\text {Grid_off }} \\
\text { Cost }_{\text {Final }}=0.9 \cdot 0.472+0.1 \cdot 1.496 \\
\text { Cost }_{\text {Final }}=0.574 \$ / \mathrm{kWh}
\end{gathered}
$$

In summary, if the generator sets are run for $10 \%$ the period of the year, the cost of electricity will increase from $0.472(\$ / \mathrm{kWh})$ to $0.574(\$ / \mathrm{kWh})$

\subsection{Estimation of Payback Period}

The payback period (PBP) is the amount of time that is expected before an investment will be returned in the form of income. In this case, the payback period is estimated with formula 17 as follow

$$
P B P=\frac{\operatorname{Cost}_{\text {NPC }}}{\text { Cost }_{\text {Annual_Net_Cash_Flow }}}
$$

$\operatorname{Cost}_{N P C}$ represents the total Net Present Cost which is estimated in table 10 below.

Cost $_{\text {Annual_Net_Cash_Flow }}$ represents the total Annual Net Cash Flow

As illustrated in Table 10. The Cost $_{N P C}$ takes into consideration the capital, replacement, operation and maintenance, fuel and salvage cost for the individual sources. The overall result is shown in right hand comer of the table. 


\begin{tabular}{|l|l|l|l|l|l|l|}
\hline Component & Capital(\$) & Replacement(\$) & O\&M(\$) & Fuel (\$) & Salvage(\$) & Total(\$) \\
\hline PV & 74,750 & 393 & 4,993 & 0 & -79 & 80,057 \\
\hline Generator & 13,4144 & 33,900 & 449,961 & 347,159 & -28 & 857,821 \\
\hline Grid & 0 & 0 & $-34,787$ & 0 & 0 & $-34,787$ \\
\hline Converter & 55,250 & 11,079 & 3,329 & 0 & -26 & 59,632 \\
\hline Other & 15,000 & 0 & 233 & 0 & 0 & 15,233 \\
\hline System & 158,414 & 1,473 & $-26,233$ & 0 & -124 & $\mathbf{9 7 7 , 9 5 6}$ \\
\hline
\end{tabular}

Table 10: Estimation of total Net Present Cost

Furthermore Cost $t_{\text {Annual_Net_Cash_Flow }}$ is estimated as follow

$$
\begin{gathered}
\text { Cost }_{\text {Annual_Net_Cash_Flow }}=\text { Cost }_{\text {Final }} \times \text { Energy }_{\text {total }} \\
\text { Cost }_{\text {Annual_Net_Cash_Flow }}=0.5744 \times 1632499 \\
\text { Cost }_{\text {Annual_Net_Cash_Flow }}=\$ 93,770.23
\end{gathered}
$$

The payback period can then be deducted in reference to Equation (18) as follow

$$
\begin{gathered}
P B P=\frac{977956.00}{93770.23} \\
P B P=10.43 \text { Years }
\end{gathered}
$$

\section{Discussion and Conclusion}

The results of this study confirm the multiple benefits of adopting a grid connected hybrid system as elaborated by previous studies (Ali et al., 2008), [4]. A limited list of the asserted benefits include "improved reliability and energy services, reduced emissions and pollution, continuous power supply, increased operational life, and reduced cost.

It is a fact that the reliability and energy services are automatically improved considering the fact that energy is being supplied from three different sources working in parallel, each of them having a high reliability. It is known that solar energy supply is very effective and efficient and also diesel generators are very reliable.

According to [2], electricity is mainly provided by diesel generators in Maldives, a country made of 1,192 island of which only 199 are inhabited. This again confirms the reliability of diesel generators. Our proposed system make use of a Grid connected solar system in which the solar power supplies almost all loads apart from the AC, a total of $234 \mathrm{kWh}$ as indicated in Table 1. The national grid takes care of the remaining load. In case www.astesj.com of power outage, the National grid goes off and the diesel generator in combination with the solar plant takes over the supply. This ensures a continuity of supply which increases the quality of energy service deliveries. Moreover Table 7 indicates savings in emission of carbon dioxide, $26.42 \mathrm{~kg} /$ year, sulfur dioxide, 115 $\mathrm{kg} /$ year and Nitrogen oxides, $56 \mathrm{~kg} /$ year.

Finally a cost analysis of the proposed hybrid system was dealt with. The levelized cost of electricity is $0.472 \$$, equivalent to GhC2.04 for a continuous supply; this cost rises to $1.496 \$ / \mathrm{kWh}$ in power outage where the load is supplied by the generator set and the solar power only. A weighted average of $0.574 \$ / \mathrm{kWh}$ is estimated in general for the year covering both the OFF and ON time of the grid within a year.

More importantly, the unit electricity cost in Ghana for energy consumption lower than $25 \mathrm{kWh} /$ month which is our case is about GhC8.39 for residential load and Gh৫24.2 for nonresidential load [14]. Therefore this study concurs with previous studies in the direction that hybrid energy systems with renewable energy sources like solar, contribute to an obvious reduction of electricity cost. The payback period of approximately ten years and half is a very good result, considering the system's viability period of 25 years.

\section{Appendix A}

\begin{tabular}{|l|l|}
\hline PV Module Ratings & Specifications \\
\hline Module Type & YL 250P-29b \\
\hline Module manufacturer & Yingli Solar \\
\hline Maximum Power (Pmax) & $250 \mathrm{Wp}$ \\
\hline Max. Power-Point Current (Imp) & $8.24 \mathrm{~V}$ \\
\hline Open-Circuit Voltage (Vmp) & $30.4 \mathrm{~V}$ \\
\hline Open-Circuit Voltage (Voc) & $38.4 \mathrm{~V}$ \\
\hline Short-Circuit Current (Isc) & $8.79 \mathrm{~A}$ \\
\hline Module Efficiency & $15.30 \%$ \\
\hline
\end{tabular}

Table A1. Specifications of Solar Panel 


\section{References}

[1] IRENA, "Off-Grid Renewable Energy Systems: Status and Methodological Issues About IRENA," 2015.

[2] C. V Nayar, "High Renewable Energy Penetration Diesel Generator Systems," Paths to Sustain. Energy, InTech, pp. 1-27, 2010.

[3] K. Sopian and M. Y. Othman, "Performance of a Photovoltaic Diesel Hybrid System In Malaysia," ISESCO Sci. Technol. Vis., vol. 1, pp. 37-39, 2005.

[4] B. Ali, K. Sopian, M. A. Rahman, Y. M. Othman, A. Zaharim, and A. M. Razali, "Performance of a Hybrid Photovoltaic Diesel System in a Cable Car Resort Facility," in 4th IASME/WSEAS International Conference on ENERGY, ENVIRONMENT, ECOSYSTEMS and SUSTAINABLE DEVELOPMENT (EEESD'08), 2008, pp. 183-187.

[5] CLUB-ER, "Rural Electrification with PV Hybrid Systems," 2013.

[6] S. Yilmaz, H. R. Ozcalik, M. Aksu, and C. Karapınar, "ScienceDirect Dynamic Simulation of a PV-Diesel-Battery Hybrid Plant for Off Grid Electricity Supply," Energy Procedia, vol. 75, pp. 381-387, 2015.

[7] M. Alam and S. Bhattacharyya, "Decentralized Renewable Hybrid Mini-Grids for Sustainable Electrification of the Off-Grid Coastal Areas of Bangladesh," Energies, vol. 9, pp. 1-16, 2016.
[8] S. Parhizi, H. Lotfi, A. Khodaei, and S. Bahramirad, "State of the art in research on microgrids: A review," IEEE Access, vol. 3, pp. 890-925, 2015.

[9] K.-L. Nguyen, D.-J. Won, S.-J. Ahn, and I.-Y. Chung, "Power Sharing Method for a Grid connected Microgrid with Multiple Distributed Generators," J. Electr. Eng. Technol., vol. 7, no. 4, pp. 459-467, 2012.

[10] A. M. Othman, H. A. Gabbar, N. Honarmand, and A. M. Othman, "Performance Analysis of Grid Connected and Islanded Modes of AC/DC Microgrid for Residential Home Cluster," Intell. Control Autom., vol. 6, pp. 249-270, 2015.

[11] H. R. Pota, M. J. Hossain, M. A. Mahmud, and R. Gadh, "Control for Microgrids with Inverter Connected Renewable Energy Resources," in IEEE PES General Meeting, 2014, pp. 1-5.

[12] A. Etxeberria, I. Vechiu, H. Camblong, J. M. Vinassa, and H. Camblong, "Hybrid Energy Storage Systems for renewable Energy Sources Integration in microgrids: A review," in IPEC, 2010, pp. 532-537.

[13] E. Aryeetey, "Guide to Electric Power in Ghana," Accra, Ghana, 2005.

[14] Electricity Company of Ghana Ltd, "Electricity Company of Ghana Limited - Current Tariff," 2016. [Online]. Available: http://www.ecgonline.info/index.php/customer-care/services/tariff. [Accessed: 22-Jan-2017]. 